\title{
Production of Biodiesel from Non Edible Cottonseed Oil by Mechanical Stirrer Technique
}

\author{
Yogendra Prasad Upadhyay ${ }^{1}$, Mr. R. B. Sharma ${ }^{2}$, Dr. Amit Pal ${ }^{3}$ \\ ${ }^{1}$ Research scholar, R.J.I.T., BSF, Academy, Tekanpur, Gwalior (M.P.) \\ ${ }^{2}$ HOD Mechanical Engineering, R.J.I.T., BSF, Academy, Tekanpur, Gwalior (M.P.) \\ ${ }^{3}$ Associate Professor, Department of Mechanical Engineering, D.T.U., Delhi
}

\begin{abstract}
In present day there is hefty demand of new and reliable alternative fuel which gives better exhaust emissions and performance on internal combustion engine. There are mainly two types of fuel that are used prominently in I.C. engines, first is gasoline like fuel which support to spark ignition engine and second that is used for compression ignition engines. The biodiesel is a renewable alternative fuel which supports to the diesel engines. The biodiesel can be produced by several numbers of feed stocks like vegetable oil, animal fats and yellow greases etc. In present researcher work the cottonseed oil (CSO) which belong to Malvaceae, the marsh mallow family, is converted to biodiesel from mechanical stirring technique. This biodiesel has been tested on a constant speed agricultural engine and found to be lower in smoke generation and almost equivalent to petro diesel on performance parameters.
\end{abstract}

Keywords: Biodiesel, Cottonseed Oil (CSO), Mechanical Stirrer Technique, I.C. Engine.

\section{Introduction}

During the last century, the utilization of energy has improved a lot due to the change in the living style and the considerable growth of population. This increase of energy stipulate has been complete by the use of fossil resources, which caused the crises of the fossil fuel diminishing, the raise in its price and the serious environmental impacts as global warming, acidification, deforestation, ozone shrinking, Eutrophication and photochemical pollution. As fossil fuels are fine sources of energy, this increasing demand for energy has lead to a search for alternative sources of energy that would be economically efficient, socially reasonable, and environmentally sound. The transport sector is a major consumer of petroleum fuels such as diesel, gasoline, liquefied petroleum gas (LPG) and compressed natural gas (CNG). Demand for transport fuels has risen considerably throughout the past few decades. The demand for transport fuel has been escalating and expectations are that this trend will continue unchanged for the coming decades. In fact, with a worldwide increasing number of vehicles and a rising demand of emerging economies, demand will probably rise even harder. The usual scarcity of petroleum supplies and the harmful environmental penalty of fossil fuels have spurred the search for renewable transportation bio fuels. Bio fuels show to be a solution to alternative fossil fuels because, resources for it will not run out, they are becoming cost wise determined with fossil fuels, they appear to be more green friendly and they are rather accessible to allocate and use as applicable transportation requirement and technologies exists and are readily available. The prospective view on bio fuels appear to be huge from an economical, supporting and environmental perspective. The energy content of bio fuels differs from conventional fuels. Total energy output per litter of bio fuel is determined by the feedstock used, province where the feedstock is grown and production techniques applied. Biodiesel production is a very modern and scientific area for researchers as an alternative fuel for diesel engines. [1] In this paper the researcher work on cottonseed oil biodiesel, is compared to petroleum diesel fuel.

The cottonseed crop is a fast growing plant with long productive life span of 3-4 months, its ability to survive on drought and poor soils at average and high temperature up to $44^{\circ} \mathrm{C}$ and a low temperature of up to $4^{\circ} \mathrm{C}$ cotton was the third biggest of the crops grown worldwide, as measured by acreage: soybean was $47 \%$, occupying 75.4 million hectares; biotech maize (51.00 million hectares at $32 \%$ ), biotech cotton ( 24.7 million hectares at 15\%) and biotech canola (8.2 million hectares at 5\%). The cotton plant (genus Gossypium) is a member of the Malvaceae, or mallow, family. In its native form, cotton grows as a perennial, but it is cultivated as an annual crop in the United States. There are dozens of cotton species native to both the Eastern and Western hemispheres and the use of cotton fibbers can be traced back thousands of years in present-day Peru and Egypt.

Fibbers grow from and are attached to the seeds, which are contained within a capsule called a boll that forms after the cotton plant flowers. As the plant matures, the bolls open to expose the fibbers and seeds (Figure 1). While propagation of the cotton plant is driven by demand for fibber to make cloth, the seeds of the cotton plant are also valuable as a food source. Oil extracted from the seeds is used for human consumption and the residual meal is fed to livestock. In recent years, uncrushed cottonseed also has been provided directly to cattle as feed. The typical ratio of seed to fibber (lint) is 3 to 2 by weight. In order for either to have value, the lint and 
seeds must be separated from one another. Cotton production is reported in terms of number of bales, which are highly compressed blocks of lint. [2]

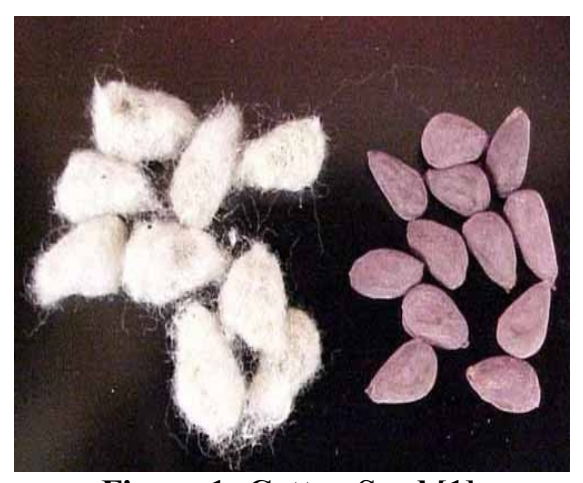

Figure 1: Cotton Seed [1]

\section{Transesterification of vegetable oil:}

Transesterification is the process of separating the fatty acids from their glycerol backbone to form fatty acid esters (FAE) and free glycerol. Fatty acid esters commonly known as biodiesel can be produced in batches or continuously by transesterifying triglycerides such as animal fat or vegetable oil with lower molecular weight alcohols in the presence of a base or an acid catalyst. This reaction occurs stepwise, with monoglycerides and diglycerides as intermediate products. The "R" groups are the fatty acids, which are usually 12 to 22 carbons in length. The large vegetable oil molecule is reduced to about $1 / 3$ its original size, lowering the viscosity making it similar to diesel fuel. The resulting fuel operates similar to diesel fuel in an engine. [35]The reaction produces three molecules of an ester fuel from one molecule of vegetable oil. In such reaction known as transesterification, a triglyceride is allowed to react with a threefold excess of an alcohol such as ethanol or methanol, and this alcohol takes the place of the ester linkage to glycerol, yielding three fatty acid esters of the new alcohol and glycerol. Above the process using methanol is shown in figure 1.2 below.

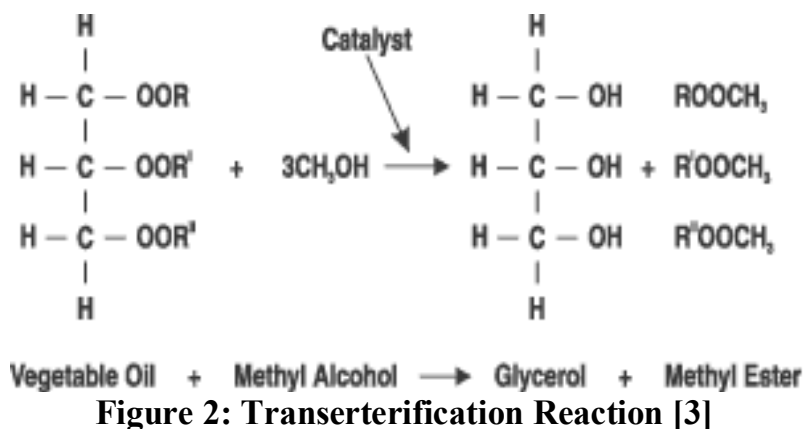

Where, term R' represents different alkyl groups. The process of transesterification brings about radical change in viscosity of vegetable oil. The biodiesel thus produced by this process is totally miscible with mineral diesel in any proportion. The overall process is normally a sequence of three consecutive steps, which are reversible reactions. In the first step from triglycerides, diglycerides are obtained. From diglyceride, monoglyceride is produced and in the last step from monoglycerides, glycerine is obtained. [6]

\section{Mechanical Stirring Technique}

Conventional mechanical stirring machine consist of temperature controller to control temperature within the range of $0-100^{\circ} \mathrm{C}$ and speed controller is for controlling speed of stirrer in terms of revolution per minute (rpm). In this machine hot plate functions as a heating source to maintain the temperature of the solution.

The beaker is placed on the hot plate then vegetable oil as per the requirement was poured into it at the beginning. The reaction started when a quantitative amount of methanol liquor dissolved in catalyst was poured into the beaker and then immediately drops the magnetic stirrer so that through its stirring action at a particular $\mathrm{rpm}$, dilution of mixture can take place by switching the button on.

\section{Working}

In a glass reactor equipped with a glass anchor-shaped stirrer, a type $\mathrm{K}$ thermocouple, a water condenser and funnel, and surrounded by a heating mantle controlled by a proportional integral derivative (PID) temperature controller device, there are use of oil that want to converted to oil and alcohol is also used in it. The 
temperature was raised up to that point, the using alcohol is not to going on evaporate and the mixture was stirred at different rpm. When this temperature was reached, and then added Potassium meth oxide. The temperature increased by two to three degrees, decreasing later to $60^{\circ} \mathrm{C}$ by the action of the PID controller. When the conversion of the oil was quantitative, the heating mantle was switched off.

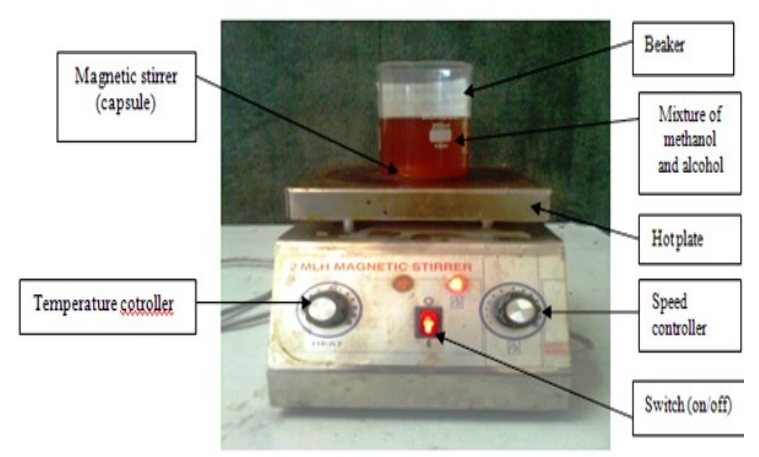

Figure 3: Mechanical starrier

The mixture was then allowed to cool in the reactor, appearing as two distinct phases after switching of the stirrer. These two phases were decanted using the bottom outlet of the reactor. The interface was composed of glycerine, water and sodium chloride. Biodiesel, used without further purification, was a clear, light yellow liquid. [6-9].

\section{Experimental work}

Conventional mechanical stirring machine consist of temperature controller to control temperature within the range of $0-100^{\circ} \mathrm{C}$ and speed controller is for controlling speed of stirrer in terms of revolution per minute (rpm). In this machine hot plate functions as a heating source to maintain the temperature of the solution.

The beaker is placed on the hot plate then vegetable oil as per the requirement was poured into it at the beginning. The reaction started when a quantities amount of methanol liquor dissolved in catalyst was poured into the beaker and then immediately drops the magnetic stirrer so that through its stirring action at a particular rpm, dilution of mixture can take place by switching the button on. The experiments are performed with alcohol to oil molar ratio as 6:1 and 4.5:1. The amount of oil, alcohol and catalyst taken is shown in Table 1.

Table 1: Experimental data of yield in mechanical stirrer technique

\begin{tabular}{|c|c|c|c|c|}
\hline \multirow{2}{*}{$\begin{array}{l}\% \text { of } \\
\text { catalys } \\
t\end{array}$} & \multicolumn{2}{|c|}{ Molar ratio 6:1 } & \multicolumn{2}{|c|}{ Molar ratio 4.5:1 } \\
\hline & $\begin{array}{l}\text { Time } \\
(\min )\end{array}$ & Yields (\%) & $\begin{array}{l}\text { Time( } \\
\text { min) }\end{array}$ & Yields (\%) \\
\hline \multirow{5}{*}{0.75} & 10 & 86.64 & 10 & 84.45 \\
\hline & 15 & 88.90 & 15 & 85.12 \\
\hline & 20 & 90.44 & 20 & 86.09 \\
\hline & 25 & 94.60 & 25 & 90.50 \\
\hline & 30 & 96.00 & 30 & 94.75 \\
\hline \multirow{5}{*}{1} & 10 & 90.11 & 10 & 86.45 \\
\hline & 15 & 91.55 & 15 & 87.78 \\
\hline & 20 & 92.48 & 20 & 88.47 \\
\hline & 25 & 95 & 25 & 92.00 \\
\hline & 30 & 98.10 & 30 & 96.60 \\
\hline
\end{tabular}

Discussion of yield percentage of biodiesel:

\section{Results}

In this work the production technique used is conventional mechanical stirrer process and use cottonseed oil as a raw material. In this work there are two types of molar ratio is $6: 1$ and 4.5:1 is consider and after that take two types of catalyst percentage $1 \%$ and $0.75 \%$ is also consider in both molar ratio. After that find the higher yield percentage is show in table 8.4 and the variation of these yields is given graph variation in figure: 


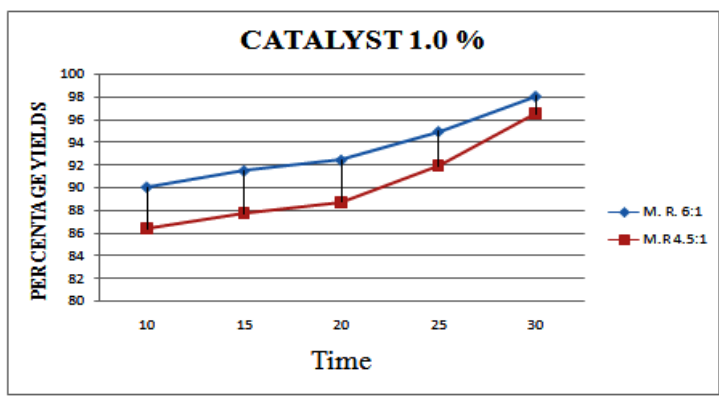

Figure 4: Time v/s Yield (\%) for catalyst percentage $1.0 \%$ and different molar ratio

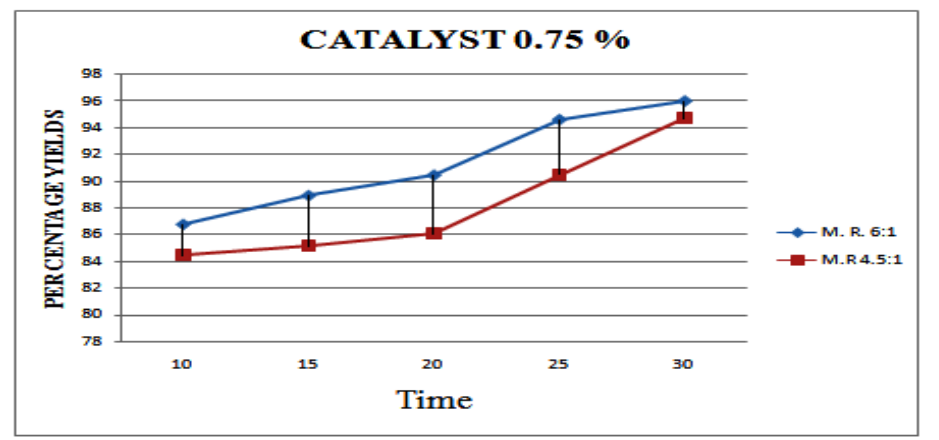

Figure 5: Time v/s Yield (\%) for catalyst percentage $0.75 \%$ and different molar ratio

\section{Conclusion}

Cottonseed oil has enormous potential for biodiesel production. The salient feature of this plant is that it grows in the form of cheaper in sandy soil with in a 3-4 months crop cycle. It is very clear that economics of the product is controlled by the availability of raw materials. So, the plantation of the trees and their usage should be properly managed to explore the benefits from this neglected plant. The important conclusions are as follows:

1)It is found that in mechanical stirring the yield obtained at $1 \% \mathrm{KOH}$ is higher as compare to $0.75 \% \mathrm{KOH}$.

2) Maximum yield up to $98 \%$ is obtained from CSO by using mechanical stirrer technique.

3) When we increase timing of stirrer the percentage of yields enhances.

4) The overall finding is that molar ratio 6:1 and timing of stirrer 30 minute is give good percentage of yields.

After that the cottonseed oil shows the better percentage of yields as compared to other non edible oils. As per experiments conducted on a constant speed agricultural engine and found to be lower in smoke generation and almost equivalent to petro diesel on performance parameters. The biodiesel also reduces the dependence on petroleum diesel oil.

\section{References}

[1]. Murphy, C.F “Analysis of innovative feedstock sources and production technologies for renewable fuels final report”. EPA: xa83379501-0

[2]. Keskina A, Guru M, Altiparmak D, and Aydin K. Using of cotton oil soap stock biodiesel-diesel fuel blends as an alternative diesel fuel, Renewable Energy 33(4) April(2008) 553-557.

[3]. Alcantara R, Amores J, Canoira L, Fidalgo E, Franco MJ, and Navarro A .Catalytic production of biodiesel from soy-bean oil, used frying oil and tallow, Biomass and Bio energy 18(6) June(2000) 515-527.

[4]. Perkins, L.A. and Peterson, C.L. Durability Testing of Transesterified Winter Rape Oil (Brassica napus L.) as Fuel in Small-Bore, Multi-cylinder, DI, CI Engines. SAE Paper No. 911764. Society of Automotive Engineers, Warren dale, PA. (1991)

[5]. Devanesan MG, Viruthagiri T and Sugumar N. Tranesterification of Jatropha oil using immobilized Pseudomonas fluorescens, African Journal of Biotechnology Vol. 6 (21), 2497-2501, 5 November, 2007.

[6]. Li S, Wang Y, Dong S, ChenY, Cao F, Chai F and Wang X. Biodiesel production from Eruca Sativa Gars vegetable oil and motor, emissions properties, Renewable Energy 34 (2009) 1871-1876.

[7]. Antolin G, Tinaut FV, Briceno Y, Castano V, Perez C and Ramrez AI .Optimisation of biodiesel production by sunflower oil Tranesterification, Bio resource Technology 83 (2002) 111-114.

[8]. Alcantara R, Amores J, Canoira L, Fidalgo E, Franco MJ and Navarro A .Catalytic production of biodiesel from soy-bean oil, used frying oil and tallow, Bio mass and Bio energy 18 (2000) 515-527.

[9]. Tashtoush GM, Al-Widyan MI and Al-Jarrah MM. Experimental study on evaluation and optimization of conversion of waste animal fat into biodiesel, Energy Conversion and Management 45 (2004) 2697-2711.

[10]. Buasri A, Chaiyut N and Phongprasit K. Prodiction of biodiesel from waste cooking oil using mixed alcohol system, KMITL Sci.J.Vol.8 No.2(Section-B)July-December 2008.

[11]. Marchetti JM, Miguel VU and Errazu AF. Possible methods for biodiesel production Renewable and Sustainable Energy Reviews] accepted 24 August 2005. 
[12]. Keskina A, Guru M, Altiparmak D and Aydin K. Using of cotton oil soap stock biodiesel-diesel fuel blends as an alternative diesel fuel, Renewable Energy 33 (2008) 553-557.

[13]. Achten WMJ, Verchot L, Franken YJ , Mathijs E , Singh VP , Aertsa R and Muysa B. Jatropha bio-diesel production and use ,Biomass and bio energy 32 (2008)1063-1084.

[14]. Peterson, C.L., Feldman, M., Korus, R., and Auld, D.L. (1991) Batch type Tranesterification process for winter rape oil. Trans. ASAE. 7(6):711-716.

[15]. Leduc S, Natarajan K,Dotzauer E, McCallum I and Obersteiner M. Optimizing biodiesel production in India, Applied Energy 86 (2009) S125-S131. 